\title{
Foliar nutrient and carbohydrate in Aralia elata can be modified by understory light quality in forests with different structures at Northeast China
}

\author{
Hongxu Wei ${ }^{1}$, Xin Chen ${ }^{1}$, Guoshuang Chen ${ }^{1}$, Hengtian Zhao ${ }^{2 \S}$
}

Wei H., Chen X., Chen G., Zhao H., 2019. Foliar nutrient and carbohydrate in Aralia elata can be modified by understory light quality in forests with different structures at Northeast China. Ann. For. Res. 62(2): 125-137.

\begin{abstract}
Many non-wood forest product (NWFP) plants are shade-obligate species, but current understanding about their foliar response to understory spectrum is quite scarce. To monitor understory light condition at large scale faces significant obstacles from heavy canopy shade and high cost of sensors arrangement. Therefore, we employed a novel methodology to meter the relative light ratio between plots under canopy and in the open-air. In this study, a number of 34 plots of natural Aralia elata populations were investigated for forest structure across six types of forests at Northeast China. Light properties of relative intensity, photosynthetic photon flux rate (PPFD), spectra in red, green, and blue wavelengths, and relative ratio of red/green, red/blue, and green/blue were measured at the height of $1.3 \mathrm{~m}$. Leaves of A. elata were collected to determined concentrations of nitrogen $(\mathrm{N})$, phosphorus $(\mathrm{P})$, starch, and soluble sugars. We found that relative blue light ratio was different among forest-types, but it had little further effect on leaf traits in A. elata. Instead, higher ratios of relative green light and green/blue depressed leaf $\mathrm{P}$ concentration. Increases in PPFD and light intensity promoted leaf $\mathrm{N}$ and $\mathrm{P}$ concentrations, respectively. The red/green ratio had adverse relationships with leaf $\mathrm{P}$ and starch concentrations in A. elata. In conclusion, due to the variation understory light condition, sites with low canopy density would benefit leaf $\mathrm{N}$ concentration and those with larger canopies can promote leaf starch accumulation in A. elata.
\end{abstract}

Keywords: cilongya, Liaodongcongmu, non-timber resource, optical condition, sustainable management

Authors. 'Northeast Institute of Geography and Agroecology, Chinese Academy of Sciences, Changchun 130102, China $\mid{ }^{2}$ Northeast Institute of Geography and Agroecology (Harbin), Chinese Academy of Sciences, Harbin 150081, China

\$ Corresponding author: Hongxu Wei (weihongxu@iga.ac.cn)

Manuscript received October 21, 2019; revised November 18, 2019; accepted November 25, 2019; online first November 26, 2019. 


\section{Introduction}

Non-wood forest products (NWFPs) are those derived from forests, shrubs, tree plantations, and tree outside forests for the utilization other than timbers (FAO 1999). The scientific culture of natural populations in forests is the main chase of developing NWFP resources (Guo et al. 2019, Nadeau \& Olivier 2003, Wei et al. 2019). Most NWFP plants are shade-obligate species with adaption to both full-light gap and closed canopy (Chandler 2017, Fournier et al. 2004, Sottile et al. 2015). The transmittance through canopy can modify the understory lighting condition and microclimate (Comeau \& Heineman 2003; Sonohat et al. 2004), thereafter change the distribution (Nunez \& de Gouvenain 2015), flora (Ou et al. 2015), and individual growth (Parker 2014) of undergrowth population. Most of the current studies took radiation intensity as the main factor that influences the understory plants, but quite less is known about the effect from more detailed light quality of spectrum. Furthermore, the physiological response of NWFP individuals to the understory light condition is less understood as well.

Red, green, and blue lights account for nearly $100 \%$ of visible light in wavelengths of $600-700 \mathrm{~nm}, 500-600 \mathrm{~nm}$, and $400-500 \mathrm{~nm}$, respectively ( $\mathrm{Li}$ et al. 2018). Controlled studies are accumulating to test the effect of specifically designed spectrum with these three lights in different composing proportions on seedlings as kinds of NWSP (Li et al. 2018; Zhao et al. 2019; Zheng et al. 2019). Lighting spectrum is directly responsible for key processes of photosynthesis (Zheng et al. 2019) and the contrasting spectra may cause reverse responses of carbohydrate production and accumulation ( $\mathrm{Li}$ et al. 2018). The metabolisms of starch and soluble sugars are both related to, or sometimes driven by, the uptake and utilization of necessary nutrients (Li et al. 2018, Wei et al. 2014, Zhao et al. 2019). Therefore, nutrient and carbohydrate are two interplayed responders to the lighting spectra. Most of these results were obtained in the laboratory. More work is needed to be conducted in field to detect the interactive responses of nutrient and carbohydrate in NWFP plants receiving transmittance.

In the ambient environment of a forest, traditional assessment of understory light environment was grossly estimated by the regression with hemispherical photography of forest canopy (Fournier et al. 2004). Former studies were limited to the stand scale with a small number of plots because of the high cost of monitoring devices (Rose \& Durako 1994; Sonohat et al. 2004). Traditional method was also queried due to the weaknesses in extensive data processing, unable resolution within closed canopy, and insufficient precision of estimate on scattered light on the surface of leaves (Capers \& Chazdon 2004). Instead, the assessment of relative light availability can cope with nearly all above-mentioned drawbacks and give more precise evaluation of understory light quality (Capers \& Chazdon 2004). The relative light quality can be measured by logging data from paired lighting meters both under canopy vs. in the open-air to quantify the stable relationship between relative light difference and percent transmittance (Capers \& Chazdon 2004, Kume et al. 2011, Rose \& Durako 1994, Wang et al. 2018).

Similarly, the relative ratio between wavelengths in a wave of lights was also found to have conclusive response to spatial alteration (Hertel et al. 2011; Hertel et al. 2012). Current findings of these field trials were used to plot the relationship between spatial variation and relative light spectra. Some studies have started to further detect on the effect of relative light spectra on photosynthetic performance of canopy surface (Hertel et al. 2012). This issue is important to understand the effect of transmittance on understory plants (Rose \& Durako 1994). However, deeper response of leaf physiology, such as foliar nutrient and carbohydrate, to relative light spectra has not attracted 
deserved attention in current literature.

Araliaceae is a large family consisting of 50 genera and 1,412 species. Aralia spp. belongs to the Araliaceae family which contains up to 71 plant-species and several of them have been taken as local NWSPs. Aralia elata (Miq.) Seem belongs to Araliaceae family as a thorny dwarf-shrub in temperate forests. A. elata is developed as both edible and medical materials widely in Northern China, Russia Far East, Japan, and Korea. A. elata contents abundant contents of triterpene saponins, the extraction of which has significant effect of countering cancer and anti-oxidation (Wang et al. 2019; Zhou et al. 2019). This merit has been highly valued by developers who has over explored the natural resource of this species. Studies revealed that $A$. elata can dwell in highly shaded environment with $80 \%$ sunlight being shaded off but their growth and biochemical properties performed the best in the $35 \%$ of transmittance (Gao et al. 2019). Natural A. elata populations tended to distribute at shallow mountains with slopes at less $10^{\circ}$ where they were shaded by canopies from complicated tree species and the responses of leaf nutrient and carbohydrate had uncertainty (Wei et al. 2019). Current studies on this species are insufficient to supply evidence to reveal the spectra effect on nutrient and carbohydrate concentrations in leaves.

China has become the world's major trader of forest products with a system of manufacturing and trading forest products under the guidance of adapting to global market and institutional forces (Ke et al. 2019). This was established following the fast development of new forest plantations from 1978 up to the latest decade which resulted in the increase of forest stock from 886 million $\mathrm{m}^{3}$ up to 1,544 million $\mathrm{m}^{3}$ (Ke et al. 2019). As a result, forests have accounted for $21.6 \%$ of national land of China in 2015 with comparison to that for $12.7 \%$ in 1978 (State Forestry Administration of China 2019). NWFP is involved in the responsibility for this fast development of forest resource utilization in China, whose development still needs more improvements with modern science and technique to follow a sustainable model. Forests at Northeast China contribute largely to the national NWFP industry especially by trading wild vegetable and medicine with organizations from Eurasian countries. A. elata is one of the most important NWFP species due to large area of natural distribution and wide demand for edible quality. In this study, natural A. elata populations were investigated for relative light spectra and foliar attributes.

Our objective was to reveal relative lighting spectra in natural $A$. elata populations of different forest types and to further detect their relationship with foliar nutrient and carbohydrate concentrations. We hypothesized that: (i) A. elata populations in different forest types were accompanied by different lighting environments varied in intensity and spectra, (ii) the variation of canopy trait accounted for different lighting spectra among forest types, and (iii) higher proportion of green light resulted in lower concentrations of nutrient and carbohydrate in leaves of $A$. elata individuals.

\section{Materials and methods}

\section{Study area}

This study was conducted in forested lands of the eastern regions in Northeast China $\left(41^{\circ} 54^{\prime}-48^{\circ} 12^{\prime} \mathrm{N}, 126^{\circ} 31^{\prime}-133^{\circ} 54^{\prime} \mathrm{E}\right)$. Forests distribute in montane areas of Jilin and Heilongjiang Provinces. The study area covered a total area was 0.28 million $\mathrm{km}^{2}$. The elevations ranged from $122 \mathrm{~m}$ to $950 \mathrm{~m}$ in slopes at angles of $0-20^{\circ}$. The mean annual temperature varied between $-4.7^{\circ} \mathrm{C}$ to $10.7^{\circ} \mathrm{C}$ with annual precipitation of $866 \mathrm{~mm}$. Averaged relative humidity $(\mathrm{RH})$ was about $65 \%$ annually. Six types of forests distributed in the study area which were dominated by Abies nephrolepis, Betula platyphylla, Larix olgensis, Pinus koraiensis, Pinus sylvestris (Table 1). Dominated trees were those 
Table 1 Information about province, city or town name, geographical distribution and forest type of plots that were investigated for natural Aralia elata populations

\begin{tabular}{|c|c|c|c|c|c|}
\hline Plot & Province & $\mathrm{C} / \mathrm{T}$ & Latitude $\left(^{\circ}\right)$ & Longitude $\left(^{\circ}\right)$ & Forest-Type \\
\hline 1 & Jilin & Jiangyuan & 41.92 & 126.52 & LOF \\
\hline 2 & Jilin & Jingyu & 42.50 & 126.78 & DBF \\
\hline 3 & Jilin & Jingyu & 42.56 & 126.80 & DBF \\
\hline 4 & Jilin & Antu & 42.29 & 128.14 & DBF \\
\hline 5 & Heilongjiang & Mudanjiang & 44.83 & 129.10 & ANF \\
\hline 6 & Heilongjiang & Mudanjiang & 44.89 & 129.26 & $\mathrm{BPF}$ \\
\hline 7 & Heilongjiang & Mudanjiang & 44.76 & 129.25 & $\mathrm{LOF}$ \\
\hline 8 & Heilongjiang & Boli & 45.69 & 130.42 & DBF \\
\hline 9 & Heilongjiang & Boli & 45.71 & 130.35 & DBF \\
\hline 10 & Heilongjiang & Boli & 45.69 & 130.55 & PSF \\
\hline 11 & Heilongjiang & Hulin & 45.88 & 132.39 & $\mathrm{BPF}$ \\
\hline 12 & Heilongjiang & Hulin & 45.95 & 132.45 & DBF \\
\hline 13 & Heilongjiang & Hulin & 45.98 & 132.62 & DBF \\
\hline 14 & Heilongjiang & Raohe & 46.93 & 133.89 & DBF \\
\hline 15 & Heilongjiang & Raohe & 46.95 & 133.90 & DBF \\
\hline 16 & Heilongjiang & Raohe & 46.80 & 133.75 & DBF \\
\hline 17 & Heilongjiang & Shuangyashan & 46.53 & 131.10 & $\mathrm{BPF}$ \\
\hline 18 & Heilongjiang & Shuangyashan & 46.43 & 131.09 & DBF \\
\hline 19 & Heilongjiang & Shuangyashan & 46.36 & 131.20 & PDF \\
\hline 20 & Heilongjiang & Jiamusi & 46.58 & 130.63 & ANF \\
\hline 21 & Heilongjiang & Jiamusi & 46.93 & 129.83 & $\mathrm{LOF}$ \\
\hline 22 & Heilongjiang & Jiamusi & 47.00 & 129.72 & PDF \\
\hline 23 & Heilongjiang & Hegang & 47.40 & 130.23 & LOF \\
\hline 24 & Heilongjiang & Hegang & 47.51 & 130.14 & LOF \\
\hline 25 & Heilongjiang & Hegang & 47.52 & 130.31 & PDF \\
\hline 26 & Heilongjiang & Yichun & 47.48 & 129.39 & BPF \\
\hline 27 & Heilongjiang & Yichun & 47.49 & 129.20 & $\mathrm{DBF}$ \\
\hline 28 & Heilongjiang & Yichun & 47.81 & 128.95 & LOF \\
\hline 29 & Heilongjiang & Wuying & 48.05 & 129.17 & ANF \\
\hline 30 & Heilongjiang & Wuying & 48.20 & 129.58 & BPF \\
\hline 31 & Heilongjiang & Wuying & 48.13 & 129.61 & PDF \\
\hline 32 & Heilongjiang & Shangzhi & 45.40 & 127.10 & DBF \\
\hline 33 & Heilongjiang & Shangzhi & 45.30 & 127.20 & DBF \\
\hline 34 & Heilongjiang & Shangzhi & 45.22 & 127.26 & PSF \\
\hline
\end{tabular}

Note. Abreviations: C/T - cities or towns, LOF - Larix olgensis, DBF - Deciduous broadleaf trees, ANF - Abies nephrolepis, BPF - Betula platyphylla, PSF - Pinus sylvestris, PDF - P. koraiensis and deciduous broadleaf mixed. 
together accounted for more than $70 \%$ of the total basal area (Wang et al. 2006). In deciduous broadleaf forests, dominated trees included B. platyphylla, Fraxinus mandshurica, Populus davidiana, Quercus mongolica, and Tilia amurensis. In some sites that were dominated by Pinus koraiensis, coexisted species included A. nephrolepis, A. palmatum, B. platyphylla, $P$. syluestriformis, and L. gmelinii.

\section{Field investigation}

Natural A. elata populations were investigated in forests within the study area from mid-July to mid-August in 2018. Stands that received investigating had to pass all of screening requirements: (i) A. elata dominated the understory layer in the density of at least 200 stems per hectare; (ii) no obvious anthropogenic influence can be found on stands; (iii) height of $A$. elata individuals were above $30 \mathrm{~cm}$; and (iv) the forest stands were dominated by timber trees. Those stands that had obvious mark of clear-cut and those as secondary coppices were excluded of the target stands. Finally, a number of 34 sites were chosen for investigating (Table 1). A plot in the area of $400 \mathrm{~m}^{2}(20$ $\mathrm{m} \times 20 \mathrm{~m}$ ) was set in each stand. Two adjacent plots needed to be away from each other in a distance of at least $5 \mathrm{~km}$. All A. elata individuals in the plot were investigated for in situ density, height, and root-collar diameter (RCD) (Table 2). Dominant trees were investigated for height $(\mathrm{TH})$, diameter at breast height $(\mathrm{DBH})$, canopy area (CA), canopy density
(CD), and stem density (SD). Five sub-plots (5 $\mathrm{m} \times 5 \mathrm{~m}$ ) were set on four near-edge corners and the center of each plot to detect relative light quality and to collect leaf samples.

Light quality was measured by a pair of photometers (Everfine PLA-20, Yuanfang Electric S\&T Inc., Hangzhou, China) simultaneously under canopy inside the plot and in the nearest open-air. Photometers were held at the height of $1.3 \mathrm{~m}$ which was closed to the mean level of $A$. elata height (Table 2). Main shade resulted from the canopy of dominant forest trees and additional shade from canopies of shrubs and saplings was avoided. Light quality was repeatedly measured in five pair of locations of sub-plots and accordingly out-of-plot positions. Data were recorded by logging stable dynamic of data since 2 min after commencement. All light conditions were monitored during the time from 10:00 am to 14:00 pm. Heavy-cloudy and rainy weathers were avoided to $\log$ data to meet the maximum light intensity of $80,000 \mathrm{Lx}$ in the open air. Optical parameters of light intensity and photosynthetic photon flux rate (PPFD) were recorded. Further percent of wavelengths in red, green, and blue lights to the PPFD in the visible light spectrum were recorded as well.

All A. elata individuals in each sub-plot were targeted as the sampling objectives. Ten to twenty leaves were collected from each individual in four orientations at the height of 0.6-1.0 $\mathrm{m}$. This height was reached by lateral branches of most individuals. Collected leaves were neither foraged by herbivores nor cov-

Table 2 Statistical description of density, height, and root-collar diameter (RCD) in Aralia elata in natural populations of forests at Northeast China

\begin{tabular}{llll}
\hline Statistics & Density (individuals ha $\left.^{-1}\right)$ & Height $(\mathrm{m})$ & RCD $(\mathrm{cm})$ \\
\hline Mean & 2004 & 1.21 & 0.33 \\
\hline Standard error & 1668 & 0.49 & 0.20 \\
\hline Median & 1333 & 1.14 & 0.28 \\
\hline Maximum & 7400 & 2.75 & 1.00 \\
\hline Minimum & 200 & 0.38 & 0.11 \\
\hline
\end{tabular}


ered by other leaves except for the tree canopy. Leaves that were about to be defoliated were excluded from the collection.

\section{Chemical analysis}

Collected leaves were dried at $68^{\circ} \mathrm{C}$ for 72 $\mathrm{h}$ and ground to pass through 60-mesh sieve (0.25 mm) (Guo et al. 2019). Dried samples were fully digested in the solution of $\mathrm{H}_{2} \mathrm{SO}_{4}$ $\mathrm{H}_{2} \mathrm{O}_{2}(7 / 3, \mathrm{v} / \mathrm{v})$ and sent for determination of $\mathrm{N}$ and $\mathrm{P}$ concentrations (Zhou et al. 2019). The $\mathrm{N}$ concentration was determined using the Kjeldahl method (UDK 152 automatic N analyser, VELP ${ }^{\circledR}$, Usmate, MB, Italy) and $\mathrm{P}$ concentration was determined by ICP-OES (Vista-MPX, $\operatorname{Varian}^{\circledR}$, CA, USA). Soluble sugars and starch concentrations were determined by the colorimetric method using a spectrophotometer at $490 \mathrm{~nm}$ (Wei et al. 2019).

\section{Statistical analysis}

Relative light quality was evaluated by two types of methodologies. Firstly, the relative ratio between two wavelengths' lights was calculated by under-canopy monitored data (Capers \& Chazdon 2004, Hertel et al. 2012, Kume et al. 2011, Rose \& Durako 1994). Another relative ratio was calculated by data from withinor out-of-canopy locations for the same spectral wavelength (Hertel et al. 2011, Wang et al. 2018). The average of five repeated loggings in a site was used as the record for one plot.

The SAS software was used for data analysis of this study (ver. 9.4 64-bit, SAS Institute, Cary, NC, USA). Data were firstly tested for the normal distribution and transformation was made when necessary. All normally distributed data were used to be tested by oneway analysis of variance (ANOVA) to detect the difference among six forest types. When significant effect was indicated by ANOVA at $P=0.05$ level, means were compared and arranged according to Duncan test $(\alpha=0.05)$ to cope with the comparison among means with uneven number of replicates. Pearson correlation was conducted twice to detect two relationships between forest structure and light quality and between both abiotic factors and leaf traits. Finally, stepwise regression was employed to detect the multiple contributions of independent variables of forest structure and light quality to leaf traits.

\section{Results}

\section{Variation among forest types}

No leaf traits showed any significant difference among forest types (Table 3). Parameters of blue light ratio and green/blue showed significant responses to different forest types. The relative blue light ratio was higher in Betula platyphylla dominated forests than that in the forests dominated by deciduous broadleaf trees by $6 \%$ (Figure 1A). In contrast, the green/ blue ratio was lower in the Betula platyphylla dominated forests by $21 \%$ (Figure 1B).

\section{Relationship between light quality and leaf trait}

Tree height and DBH had positive relationships with red/blue ratio and relative red quality, respectively (Table 4). However, canopy density was negatively correlated to the blue light ratio. DBH had a positive relationship with leaf $\mathrm{P}$ concentration (Table 5). Thereafter, its relationship with the ratio of $\mathrm{N}$ to $\mathrm{P}$ concentrations in leaves $(\mathrm{N} / \mathrm{P})$ turned to be negative. PPFD had a positive relationship with both leaf $\mathrm{N}$ and $\mathrm{P}$ concentrations but its relationship with N/P was inverse to be negative (Table 5). The relative green light ratio had a negative relationship with leaf $\mathrm{P}$ concentration but a positive relationship with N/P. Relative light ratios of green/blue and red/green were negative to leaf phosphorus and starch concentrations, re- 
Table 3 Analysis of variance (ANOVA) of different forest type on understory light quality and foliar nutrition and carbohydrate concentrations of Aralia elata in natural within-forest populations at Northeast China

\begin{tabular}{llrrll}
\hline Parameters & DF & Type-I SS & \multicolumn{1}{l}{ MS } & $F$ & \multicolumn{1}{l}{$P \mathrm{r}>F$} \\
\hline PPFD & 5 & 1.2444 & 0.2489 & 1.21 & 0.3282 \\
\hline Red & 5 & 5.0372 & 1.0075 & 0.92 & 0.4844 \\
\hline Green & 5 & 2.8130 & 0.5626 & 0.79 & 0.5673 \\
\hline Blue & 5 & 0.0228 & 0.0046 & 3.62 & 0.0119 \\
\hline Red/Blue & 5 & 1.3790 & 0.2758 & 0.35 & 0.8800 \\
\hline Green/Blue & 5 & 41.9847 & 8.3969 & 3.93 & 0.0080 \\
\hline Red/Green & 5 & 0.0334 & 0.0067 & 0.19 & 0.9649 \\
\hline Intensity & 5 & 0.7190 & 0.1438 & 1.28 & 0.2995 \\
\hline Nitrogen & 5 & 174.3243 & 34.8649 & 1.10 & 0.3814 \\
\hline Phosphorus & 5 & 4.4884 & 0.8977 & 1.74 & 0.1589 \\
\hline Starch & 5 & 1552.0500 & 310.5000 & 1.40 & 0.2537 \\
\hline Soluble sugars & 5 & 4.5164 & 0.9033 & 0.67 & 0.6507 \\
\hline
\end{tabular}

Note. Abreviations: DF - degree of freedom, SS - sum of squares, MS - mean square, PPFD - photosynthetic photon flux rate; red, green and blue, relative ratio of understory lights to those in the open-air; red/blue, green/blue and red/green are the ratios of two lights in understory populations. spectively (Table 5). Light intensity had a positvie relationship with leaf $P$ concentration but a negative relationship with N/P.

\section{Relationship between light quality and leaf trait}

The stepwise regression analysis indicated that canopy density and PPFD had adverse contributions to leaf $\mathrm{N}$ concentration (Table 6). The positive contributing of PPFD was much larger than the negative contibution of CD. Relative green light ratio and red/green ratio also had adverse contributions to leaf $P$ concentration and the positive effect from red/green ratio was larger. Canopy area and understory red/ green had inverse contributions to leaf starch concentration whereas the effect of canopy area was positive (Table 6).
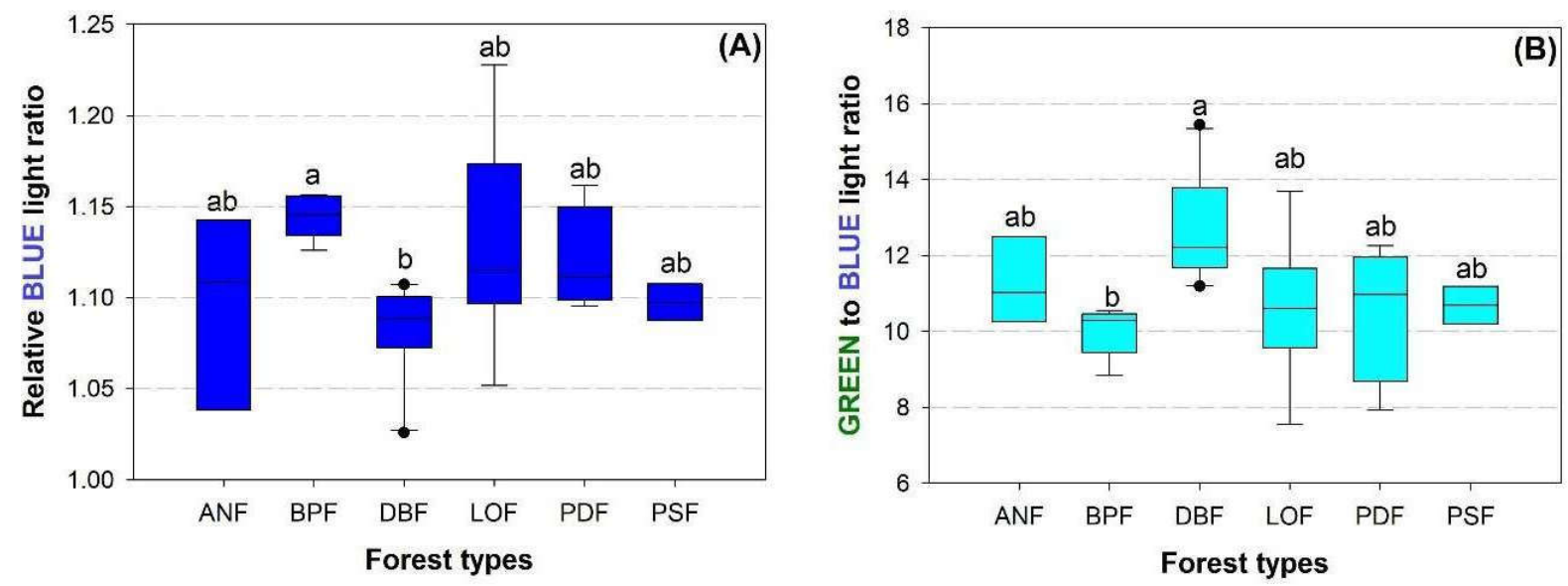

Figure 1 Boxplots of data about ratio of understory blue light to that under the open-air ANF (data transformed by the cube root of raw data plus $0.4 \%$ ) (A) and green to blue lights in the understory Aralia elata populations (B) among different forest types. Abreviations: ANF - Abies nephrolepis, BPF - Betula platyphylla, DBF - Deciduous broadleaf trees, LOF - Larix olgensis, PDF - P. koraiensis and deciduous broadleaf mixed, SF - Pinus sylvestris. Different letters indicate significant difference of means according to Duncan test at 0.05 level 
Table 4 Pearson correlation between variables about forest structure and the understory light quality showing coefficients of regression determinative $(R)$ and probability value $(P)(n=34)$

\begin{tabular}{llllllllll}
\hline $\begin{array}{l}\text { Vari- } \\
\text { ables }\end{array}$ & $\begin{array}{l}\text { Coeffi- } \\
\text { cients }\end{array}$ & PPFD & Red & Green & Blue & $\begin{array}{l}\text { Red/ } \\
\text { Blue }\end{array}$ & $\begin{array}{l}\text { Green/ } \\
\text { Blue }\end{array}$ & $\begin{array}{l}\text { Red/ } \\
\text { Green }\end{array}$ & Intensity \\
\hline \multirow{2}{*}{ TreeH } & $R$ & -0.1011 & 0.0355 & 0.0856 & -0.0731 & 0.4136 & 0.1587 & -0.0155 & -0.0818 \\
\cline { 2 - 10 } & $P$ & 0.5695 & 0.8420 & 0.6304 & 0.6813 & 0.0150 & 0.3700 & 0.9308 & 0.6458 \\
\hline \multirow{2}{*}{ DBH } & $R$ & 0.3831 & 0.0682 & -0.3353 & 0.2283 & -0.1636 & -0.3351 & 0.1020 & 0.1160 \\
\cline { 2 - 10 } & $P$ & 0.0253 & 0.7017 & 0.0526 & 0.1941 & 0.3552 & 0.0527 & 0.5660 & 0.5136 \\
\hline \multirow{2}{*}{ CA } & $R$ & 0.2092 & 0.0910 & -0.2320 & 0.0328 & 0.0416 & -0.1559 & 0.0771 & -0.0038 \\
\cline { 2 - 10 } & $P$ & 0.2350 & 0.6090 & 0.1867 & 0.8538 & 0.8152 & 0.3786 & 0.6646 & 0.9830 \\
\hline \multirow{2}{*}{ SD } & $R$ & -0.0276 & -0.0748 & -0.1921 & 0.1820 & -0.0647 & -0.2307 & 0.0578 & 0.1080 \\
\cline { 2 - 10 } & $P$ & 0.8769 & 0.6742 & 0.2764 & 0.3029 & 0.7162 & 0.1892 & 0.7454 & 0.5432 \\
\hline \multirow{2}{*}{$\mathrm{CD}$} & $R$ & -0.0649 & -0.1713 & 0.1275 & -0.3660 & 0.1822 & 0.1916 & -0.1401 & -0.0124 \\
\cline { 2 - 9 } & $P$ & 0.7154 & 0.3326 & 0.4724 & 0.0333 & 0.3025 & 0.2776 & 0.4296 & 0.9447 \\
\hline
\end{tabular}

Note. Abreviations: PPFD - photosynthetic photon flux rate; red, green and blue, relative ratio of understory lights to those in the open-air; red/blue, green/blue and red/green are the ratios of two lights in understory populations; TreeH, tree height; DBH - diameter at breast height; CA - canopy area; SD - stem density; CD - canopy density.

Table 5 Pearson correlation between variables about forest structure and the understory light quality and leaf nutrient and carbohydrate concentrations in Aralia elata showing coefficients of regression determinative $(R)$ and probability value $(P)$

\begin{tabular}{llrrrrr}
\hline Variables & Coefficients & Nitrogen & Phosphorus & $\mathrm{N} / \mathrm{P}$ & Starch & Sugar \\
\hline \multirow{2}{*}{ TreeH } & $R$ & -0.0819 & -0.2554 & 0.1703 & 0.0952 & -0.1166 \\
\cline { 2 - 7 } DBH & $P$ & 0.6451 & 0.1449 & 0.3356 & 0.5923 & 0.5114 \\
\hline \multirow{2}{*}{ CA } & $R$ & 0.2785 & 0.4172 & -0.3686 & 0.2422 & -0.1283 \\
\cline { 2 - 7 } & $P$ & 0.1107 & 0.0141 & 0.0319 & 0.1676 & 0.4696 \\
\hline \multirow{2}{*}{ SD } & $P$ & 0.0883 & 0.3107 & 0.0281 & 0.3301 & -0.2628 \\
\hline \multirow{2}{*}{ CD } & $R$ & 0.6196 & 0.0737 & 0.8746 & 0.0566 & 0.1332 \\
\hline \multirow{2}{*}{ PPFD } & $P$ & -0.1429 & 0.2685 & -0.1939 & -0.1406 & 0.1090 \\
\hline \multirow{2}{*}{ Red } & $P$ & 0.4201 & 0.1246 & 0.2719 & 0.4278 & 0.5396 \\
\hline & $P$ & -0.1414 & 0.2087 & 0.1671 & 0.0044 & -0.3048 \\
\hline
\end{tabular}


Table 5 (continuation)

\begin{tabular}{llrrrrr}
\hline \multirow{2}{*}{ Green } & $R$ & -0.1796 & -0.5054 & 0.3888 & 0.1396 & -0.0391 \\
\cline { 2 - 7 } Blue & $P$ & 0.3094 & 0.0023 & 0.0230 & 0.4312 & 0.8263 \\
\hline \multirow{2}{*}{ Red/Blue } & $R$ & 0.0892 & 0.2170 & -0.1480 & 0.1585 & -0.1684 \\
\cline { 2 - 7 } & $P$ & 0.6159 & 0.2178 & 0.4036 & 0.3705 & 0.3410 \\
\hline \multirow{2}{*}{ Green/Blue } & $P$ & 0.1207 & -0.2656 & 0.3281 & 0.3331 & -0.2951 \\
\cline { 2 - 7 } & $R$ & 0.4965 & 0.1290 & 0.0582 & 0.0542 & 0.0902 \\
\hline \multirow{2}{*}{ Red/Green } & $P$ & -0.2621 & -0.4410 & 0.2761 & -0.1512 & 0.1710 \\
\hline \multirow{2}{*}{ Intensity } & $R$ & 0.1343 & 0.0090 & 0.114 & 0.3933 & 0.3336 \\
\hline
\end{tabular}

Note. Abreviations: N/P - leaf ratio of nitrogen to phosphorus concentrations; TreeH - tree height; DBH - diameter at breast height; CA - canopy area; SD - stem density; CD - canopy density; PPFD - photosynthetic photon flux rate; red, green and blue, relative ratio of understory lights to those in the open-air; red/blue, green/blue and red/ green are the ratios of two lights in understory populations.

\section{Discussion}

Forests dominated by broadleaf trees showed more variation in understory light condition than other types of forests. The birch forests showed lower green/blue ratio because of higher understory blue light was retained in transmittance through canopy. Previous studies also revealed a higher proportion of blue light ratio in visible lights in birch forests than other forests (An et al. 2019). Our results also revealed that the blue light ratio was higher in forests with lower canopy density. Hence, the low level of density canopy in birch forests ( $\sim 53 \%$ compared to $\sim 60 \%$ in others) resulted in the higher blue light ratio therein. The blue range in visible spectrum is characterized by low reflectance and high absorption (Hertel et al. 2011). The absorption of blue light by chlorophyll is even higher than red light (Combes et al. 2000; Grant 1997). Therefore, an open canopy decreased the absorption of blue light by leaves resulting in higher proportion of blue light ratio left in the understory layer.

A Higher canopy results in larger understory space that receives sunlight. The positive correlation between tree height and red/blue ratio found in this study concurs with that in Hertel et al. (Hertel et al. 2011). As it was interpreted, broadleaf tree leaves extracted more red lights than blue ones (Hertel et al. 2011; Hertel et al. 2012). Hence, a higher canopy allowed more red light left in the understory spectrum. Although it was ever reported that height of broadleaf trees would depress understory PPFD (Comeau \& Heineman 2003), our results did not show similar results due to lack of significant statistical correlation. Instead, DBH had a positive relationship with understory PPFD. These results did not concur with another study on forests in France and Belgium where authors found a clear negative relationship between diameter and PPFD (Sonohat et al. 2004). Our results, however, generated because stands with trees of coarser stems were found to have less shade from undergrowth shrubs and coppices. In contrast, the understory space of those stands with thinner-stem trees tended to be occupied by shrubs that generated more shade on PPFD at the height of $1.3 \mathrm{~m}$.

It was interesting to find that DBH of dominant trees was correlated with leaf $\mathrm{P}$ concen- 
Table 6 Summary of stepwise regression of contributions by forest structure and understory light quality to foliar nutrition and carbohydrate concentrations of Aralia elata in natural populations of Northeast China

\begin{tabular}{|c|c|c|c|c|c|c|c|}
\hline $\begin{array}{l}\text { Dependent } \\
\text { variables }\end{array}$ & Variable & $\begin{array}{r}\text { Parameter } \\
\text { estimate }\end{array}$ & $\mathrm{SE}^{1}$ & $\mathrm{SS}^{2}$ & $R$ square & $F$ value & $P \mathrm{r}>F$ \\
\hline \multirow{4}{*}{ Nitrogen } & Model & - & - & 323.0529 & 161.5264 & 6.79 & 0.0036 \\
\hline & Intercept & 11.1598 & 2.8652 & 360.6314 & - & 15.17 & 0.0005 \\
\hline & $\mathrm{CD}^{3}$ & -0.0844 & 0.0409 & 101.0942 & 0.3048 & 4.25 & 0.0477 \\
\hline & $\mathrm{PPFD}^{4}$ & 5.8858 & 1.8491 & 240.8501 & 0.2094 & 10.13 & 0.0033 \\
\hline \multirow{4}{*}{ Phosphorus } & Model & - & - & 8.8124 & 4.4062 & 13.46 & $<0.0001$ \\
\hline & Intercept & 5.7846 & 0.3647 & 82.3457 & - & 251.57 & $<0.0001$ \\
\hline & Green $^{5}$ & -0.9279 & 0.1799 & 8.7134 & 0.2554 & 26.62 & $<0.0001$ \\
\hline & Red/Green ${ }^{6}$ & 2.9461 & 0.8460 & 3.9692 & 0.4648 & 12.13 & 0.0015 \\
\hline \multirow{4}{*}{ Starch } & Model & - & - & 2206.4379 & 1103.2189 & 6.17 & 0.0055 \\
\hline & Intercept & 54.2592 & 11.9186 & 3705.2258 & - & 20.72 & $<0.0001$ \\
\hline & $\mathrm{CA}^{7}$ & 22.0316 & 9.2587 & 1012.3056 & 0.2848 & 5.66 & 0.0237 \\
\hline & Red/Green & -36.4595 & 13.2087 & 1362.1368 & 0.1541 & 7.62 & 0.0096 \\
\hline \multirow{2}{*}{ Sugar } & Model & - & - & - & - & - & - \\
\hline & Intercept & 2.6471 & 0.1943 & 238.2353 & - & 185.58 & $<0.0001$ \\
\hline
\end{tabular}

Note. Abreviations: SE - standard error; SS - sum of square; CD - canopy density; PPFD - photosynthetic photon flux rate; Green, relative ratio of understory green light to that in the open-air; Red/Green is the ratios of red to green lights in understory populations; CA, canopy area.

tration in $A$. elata individuals. These results suggest that the uptake of $\mathrm{P}$ by natural $A$. elata individuals synchronized with the diameter growth of dominant trees in a same stand without competition. The synchronization between understory leaf $\mathrm{P}$ concentration and tree-stem growth was also found in subtropical plantations (Fan et al. 2015; Scowcroft et al. 2008). The null response of leaf $\mathrm{N}$ concentration in A. elata agrees to that in Wei et al. (Wei et al. 2019). Growth of A. elata appears to be limited more heavily by $\mathrm{P}$ than by $\mathrm{N}$.

Higher understory PPFD can favor both $\mathrm{N}$ and $\mathrm{P}$ uptake resulting in higher nutrient concentrations in leaves. However, the uptake of $\mathrm{P}$ by the impact of PPFD was faster than $\mathrm{N}$ because of the negative relationship between N/P and PPFD. Another negative relationship was also found between light intensity and leaf $P$ concentration followed by the decline in N/P.
These together indicate the tendency that leaf $\mathrm{N}$ was more driven by PPFD while leaf $\mathrm{P}$ more by light intensity. Our results concur with another study on Macadamia integrifolia (Huett et al. 2001) and Chaetoceros muelleri (Leonardos \& Geider 2004). In A. elata the change of leaf $\mathrm{N} / \mathrm{P}$ is coregulated by either $\mathrm{N}$ or $\mathrm{P}$ concentrations in response to abiotic change (Wei et al. 2019). The negative relationship between PPFD or light intensity and N/P can also be interpreted into higher N/P at low light availability. The change of PPFD drove the demand of $\mathrm{N}$ for growth hence in low lights not so much $\mathrm{N}$ was absorbed as the need for growth declined (Lewis \& Tanner 2000). Light intensity failed to change leaf $\mathrm{N}$ concentration because this meter on lighting condition does not have as much relations with photons delivery as PPFD. However, both light intensity and PPFD had a strong effect on P uptake which 
indicated that natural $A$. elata population was probably suffering $\mathrm{P}$ deficiency (Leonardos \& Geider 2004, Lewis \& Tanner 2000). Our study was not alone to reveal the potential of $\mathrm{P}$ limit to A. elata (Wei et al. 2019). More work is needed in the future to confirm this speculation.

Our results partly support the hypothesis by that the green light had a negative relationship with $\mathrm{P}$ uptake so did the green-light-driven green/blue and red/green ratios. Zhao et al. reported that the green-tended spectrum from light-emitting diodes (LEDs) induced higher P concentration in stems of Larix principis-rupperchtii seedlings than the red-tended spectrum (Zhao et al. 2019). In another study on Dalbergia odorifera seedlings, however, the green-tended spectrum failed to affect the P uptake (Li et al. 2018). To our knowledge, quite little of other evidence has been documented to supply more information about the green-light effect on $\mathrm{P}$ uptake in plants. A summary on plants' response to the green light in the past five decades indicated that current understanding about green lights has accumulated to reveal the function and effect on plant biology but plants' sense of this light quality is generally lack of elucidating (Folta $\&$ Maruhnich 2007). Furthermore, the effect from green light on plant processes results from means via cryptochrome-dependent and cryptochrome-independent approaches which oppose those directed by red and blue wavelengths (Folta \& Maruhnich 2007). More studies are needed to reveal more exact mechanism for the green light effect on P uptake.

It is well documented that understory are shade-obligate species. Gao et al. reported that the $50-65 \%$ shading resulted in the highest level of soluble sugars in A. elata leaves (Gao et al. 2019). Our study concurs with this judgment by finding higher leaf starch accumulation in A. elata individuals under larger canopies. We further revealed that the lower red/green ratio from the understory light condition determined the increase of leaf starch concentration. Several studies found the rapid decline of red light ratio in spectrum along the lights emitting deep in the canopy due to foliar absorption of this wavelength of light (Capers \& Chazdon 2004; Hertel et al. 2011). The reflection of green light from the surface of leaves contributed to the decline of red/green ratio under canopy. Red light can fuel starch accumulation by increasing the amount and activity of enzymes that function for carbon fixation through the phytochrome system (Ma et al. 2017, Yagi et al. 1994). Null response by leaf sugar concentration result from inactive hydrolyzation of starch granules caused by abiotic stresses.

\section{Conclusions}

In this study, using the measures of relative light quality methodology we found relationship between understory light condition and leaf traits in Aralia elata in various forest types. The relative blue light was found to be the only factor that was different among different forest types. However, blue light had no further effect on any of leaf parameters in $A$. elata. Instead, higher ratios of relative green light and green/blue were found to depress leaf $\mathrm{P}$ concentration. The red/green ratio can be taken as an optical indicator to broadcast the leaf $\mathrm{P}$ and starch concentrations by positive and negative contributions, respectively. Our study has practical meaning for the management of natural A. elata populations in northeast forests. Forests with low canopy density would benefit $\mathrm{N}$ uptake in $A$. elata and those with more expanded canopies can promote starch accumulation in leaves.

\section{Acknowledgments}

This research was funded by the National Key Research and Development Program of China (grant number 2016YFC0500300), the 
Strategic Priority Research Program of the Chinese Academy of Sciences (grant number XDA23070503), National Natural Science Foundation of China (grant number 41971122; 41861017; 31600496), the Regional Key Project in S\&T Services Network Program of Chinese Academy of Sciences (grant number KFJSTS-QYZD-044; KFJ-STS-ZDTP-048), and the Funding for Jilin Environmental Science (grant number 2017-16).

\section{References}

An B.Y., Wang D., Liu X.J., Guan H.M., Wei H.X., Ren Z.B., 2019. The effect of environmental factors in urban forests on blood pressure and heart rate in university students. Journal of Forest Research 24: 27-34. DOI: 10.1080/13416979.2018.1540144

Capers R.S., Chazdon R.L., 2004. Rapid assessment of understory light availability in a wet tropical forest. Agricultural and Forest Meteorology 123: 177-185. DOI: 10.1016/j.agrformet.2003.12.009

Chandler J.L., 2017. A slow opportunist: physiological and growth responses of an obligate understory plant to patch cut harvesting. Oecologia 183: 677-687. DOI: 10.1007/s00442-017-3808-5

Combes D., Sinoquet H., Varlet-Grancher C., 2000. Preliminary measurement and simulation of the spatial distribution of the Morphogenetically Active Radiation (MAR) within isolated tree canopy. Annals of Forest Science 57: 497-511. DOI: 10.1051/forest:2000137

Comeau P.G., Heineman J.L., 2003. Predicting understory light microclimate from stand parameters in young paper birch (Betula papyrifera Marsh.) stands. Forest Ecology and Management 180: 303-315. DOI: 10.1016/ S0378-1127(02)00581-9

Fan H.B., Wu J.P., Liu W.F., Yuan Y.H., Hu L., Cai Q.K., 2015. Linkages of plant and soil C:N:P stoichiometry and their relationships to forest growth in subtropical plantations. Plant and Soil 392: 127-138. DOI: 10.1007/ s11104-015-2444-2

FAO, 1999. Towards a harmonized definition of non-wood forest products. Unasylva 50: 1999/1993

Folta K.M., Maruhnich S.A., 2007. Green light: a signal to slow down or stop. Journal of Experimental Botany 58: 3099-3111. DOI: 10.1093/jxb/erm130

Fournier A.R., Gosselin A., Proctor J.T.A., Gauthier L., Khanizadeh S., Dorais M., 2004. Relationship between understory light and growth of forest-grown american ginseng (Panax quinquefolius L.). Journal of the American Society for Horticultural Science 129: 425-432. DOI: 10.21273/JASHS.129.3.0425

Gao Z., Khalid M., Jan F., Saeed ur R., Jiang X., Yu X., 2019. Effects of light-regulation and intensity on the 136 growth, physiological and biochemical properties of Aralia elata (miq.) seedlings. South African Journal of Botany 121: 456-462. DOI: 10.1016/j.sajb.2018.12.008

Grant R.H., 1997. Partitioning of biologically active radiation in plant canopies. International Journal of Biometeorology 40: 26-40. DOI: 10.1007/BF02439408

Guo S., Wei H., Li J., Fan R., Xu M., Chen X., Wang Z., 2019. Geographical distribution and environmental correlates of eleutherosides and isofraxidin in Eleutherococcus senticosus from natural populations in forests at Northeast China. Forests 10: 872. DOI: 10.3390/ f10100872

Hertel C., Leuchner M., Menzel A., 2011. Vertical variability of spectral ratios in a mature mixed forest stand. Agricultural and Forest Meteorology 151: 1096-1105. DOI: 10.1016/j.agrformet.2011.03.013

Hertel C., Leuchner M., Rotzer T., Menzel A., 2012. Assessing stand structure of beech and spruce from measured spectral radiation properties and modeled leaf biomass parameters. Agricultural and Forest Meteorology 165: 82-91. DOI: 10.1016/j.agrformet.2012.06.008

Huett D.O., Gogel B.J., Meyers N.M., McConchie C.A., McFadyen L.M., Morris S.C., 2001. Leaf nitrogen and phosphorus levels in macadamias in response to canopy position and light exposure, their potential as leaf-based shading indicators, and implications for diagnostic leaf sampling protocols. Australian Journal of Agricultural Research 52: 513-522. DOI: 10.1071/AR00066

Ke S.F., Qiao D., Zhang X.X., Feng Q.Y., 2019. Changes of China's forestry and forest products industry over the past 40 years and challenges lying ahead. Forest Policy and Economics 106: 101949. DOI: 10.1016/j. forpol.2019.101949

Kume A., Nasahara K.N., Nagai S., Muraoka H., 2011. The ratio of transmitted near-infrared radiation to photosynthetically active radiation (PAR) increases in proportion to the adsorbed PAR in the canopy. Journal of Plant Research 124: 99-106. DOI: 10.1007/s10265010-0346-1

Leonardos N., Geider R.J., 2004. Responses of elemental and biochemical composition of Chaetoceros muelleri to growth under varying light and nitrate: phosphate supply ratios and their influence on critical N: P. Limnological Oceanography 49: 2105-2114. DOI: $10.4319 /$ 10.2004.49.6.2105

Lewis S.L., Tanner E.V.J., 2000. Effects of above- and belowground competition on growth and survival of rain forest tree seedlings. Ecology 81: 2525-2538. DOI: 10.1890/0012-9658(2000)081[2525:EOAABC]2.0. $\mathrm{CO} ; 2$

Li X.W., Chen Q.X., Lei H.Q., Wang J.W., Yang S., Wei H.X., 2018. Nutrient uptake and utilization by Fragrant rosewood (Dalbergia odorifera) seedlings cultured with oligosaccharide addition under different lighting spectra. Forests 9: 15. DOI: 10.3390/f9010029

Ma L., Xue N., Fu X.Y., Zhang H.S., Li G., 2017. Arabidopsis thaliana FAR-RED ELONGATED HYPOCOTYLS3 (FHY3) and FAR-RED-IMPAIRED 
RESPONSE1 (FAR1) modulate starch synthesis in response to light and sugar. New Phytologyst 213: 16821696. DOI: $10.1111 / \mathrm{nph} .14300$

Nadeau I., Olivier A., 2003. The biology and forest cultivation of American ginseng (Panax quinquefolius L.) in Canada. Canadian Journal of Plant Science 83: 877891. DOI: $10.4141 / \mathrm{P} 02-092$

Nunez H.R., de Gouvenain R.C., 2015. Seasonal variation in understory light near a gap edge and its association with conifer seedling survival in a Southern New England forest. Northeast Naturalist 22: 613-629. DOI: 10.1656/045.022.0315

Ou Z.Y., Cao J.Z., Shen W.H., Tan Y.B., He Q.F., Peng Y.H., 2015. Understory flora in relation to canopy structure, soil nutrients, and gap light regime: a case study in Southern China. Polish Journal of Environmental Studies 24: 2559-2568. DOI: $10.15244 /$ pjoes/59238

Parker W.C., 2014. The relationship of stand structure with canopy transmittance: Simple models and practical methods for managing understory light conditions in eastern white pine (Pinus strobus L.)-dominated forests. Forestry Chronicle 90: 489-497. DOI: 10.5558/ tfc2014-099

Rose C.D., Durako M.J., 1994. Induced photomorphogensis by an altered R-FR light ratio in Axenic ruppia-maritima L. Botanica Marina 37: 531-535. DOI: 10.1515/ botm.1994.37.6.531

Scowcroft T.G., Haraguchi J.E., Fujii D.A., 2008. Understory structure in a 23-year-old Acacia koa forest and 2-year growth responses to silvicultural treatments. Forest Ecology and Management 255: 1604-1617. DOI: 10.1016/j.foreco.2007.11.019

Sonohat G., Balandier P., Ruchaud F., 2004. Predicting solar radiation transmittance in the understory of even-aged coniferous stands in temperate forests. Annals of Forest Science 61: 629-641. DOI: 10.1051/forest:2004061 DOI: 10.1051/forest:2004061

Sottile G.D., Meretta P.E., Tonello M.S., Bianchi M.M., Mancini M.V., 2015. Disturbance induced changes in species and functional diversity in southern Patagonian forest-steppe ecotone. Forest Ecology and Management 353: 77-86. DOI: 10.1016/j.foreco.2015.05.025

State Forestry Administration of China 2019. Building an ecological civilization and creating a beautiful country.
Greentimes. Web: http://www.forestry.gov.cn/main/106 5/20190125/173240086175742.html. Accessed 25 January 2019

Wang W. et al., 2019. Eclalbasaponin I. causes mitophagy to repress oxidative stress-induced apoptosis via activation of $\mathrm{p} 38$ and ERK in SH-SY5Y cells. Free Radical Research 53: 655-668. DOI: 10.1080/10715762.2019.1620937

Wang W.J., Zhan B., Xiao L., Zhou W., Wang H.M., He X.Y., 2018. Decoupling forest characteristics and background conditions to explain urban-rural variations of multiple microclimate regulation from urban trees. PeerJ 6: 25. DOI: 10.7717/peerj.5450

Wei H.X., Xu C.Y., Ma L.Y., Duan J., Jiang L.N., Ren J., 2014. Effect of late-season fertilization on nutrient reserves and carbohdyrate accumulation in bareroot Larix olgensis seedlings. Journal of Plant Nutrition 37: 279293. DOI: 10.1080/01904167.2013.859697

Wei H.X., Zhao H.T., Chen X., 2019. Foliar N:P stoichiometry in Aralia elata distributed on different slope degrees. Notulae Botanicae Horti Agrobotanici 47: 887895. DOI: $10.15835 /$ nbha47311390

Yagi K. et al., 1994. Stimulatory effect of red light on starch accumulation in a marine green alga,chlamydomonas sp. strain MGA161. Applied Biochemestry and Biotechnology 45-6: 225-232. DOI: 10.1007/ BF02941801

Zhao J. et al., 2019. Nutrient uptake and utilization in Prince Rupprecht's larch (Larix principis-rupprechtii Mayr.) seedlings exposed to a combination of light-emitting diode spectra and exponential fertilization. Soil Science and Plant Nutrition 65: 358-368. DOI: $10.1080 / 00380768.2019 .1631715$

Zheng L., Ceusters J., Van Labeke M.C., 2019. Light quality affects light harvesting and carbon sequestration during the diel cycle of crassulacean acid metabolism in Phalaenopsis. Photosynthesis Research 141: 195-207. DOI: $10.1007 / \mathrm{s} 11120-019-00620-1$

Zhou W., Zhao L.B., Yuan H.Y., Xu L., Tan W.H., Song Y.M., Fang X.H., 2019. A new small cell lung cancer biomarker identified by Cell-SELEX generated aptamers. Experimental Cell Research 382: 8. DOI: 10.1016/j. yexcr.2019.06.023 